\title{
Identification of Technical Requirement for Improving Quality of Local Online Food Delivery Service in Yogyakarta
}

\author{
Cecilia Desvita Ratna Elvandari'1,Anggoro Cahyo Sukartiko*,1 and Arita Dewi \\ Nugrahini1
}

1Department of Agro-industrial Technology, Faculty of Agricultural Technology

Universitas Gadjah Mada, Jl. Flora 1 Bulaksumur Yogyakarta, 55281 Indonesia.

Email: cahyos@ugm.ac.id*

\begin{abstract}
Increased internet usage and fast-paced consumer's demands have created business opportunities, including online food delivery services. However, competition with similar national-scale businesses allegedly contributed to the decline in the number of XYZ company orders, one of the food-delivery service providers in Yogyakarta. Therefore, this study aimed to identify the need's attributes of the daring food delivery service consumers, to find out the servicequality satisfaction level, and to determine the technical requirement for improving the delivery service. The combination of Servqual and Quality Function Deployment (QFD) were then used to reach the research goals. The online survey instruments, which were borrowed from the previous studies and adapted for this study, were distributed from June 2016 to February 2017 to more than 700 XYZ's consumers, with the number of respondents who answered as many as 213 peoples. Cronbach's Alpha, the most common test for multiple Likert questions in a survey, was then used for analyzing the collected data. The result shows that order conformity; politeness and friendliness of messengers and administrative workers; cleanliness of food box; a good conditionof received ordered food; and affordable delivery costs are the top five attributes of consumer needs. Meanwhile, the top five observed technical requirements are the provision of skills training to messengers and administrative workers; periodic evaluations of service performance; the regular addition of food outlet members; providing map feature on the company website, and provision of ordering applications. The identified requirements can benefit local food delivery service providers in competing with national scale competitors and adapt to disruptive age.
\end{abstract}

Keywords: Online food delivery service, QFD, servqual.

\section{INTRODUCTION}

Internet usage in Indonesia is increasing with most users (>63\%) having online shopping experience [1]. Meanwhile, food and beverage products, ranked fifth ( $>7 \%)$ as the most widely sold products online [1]. This situation has provided an online food delivery service opportunity that provides convenience and choice for consumers, including in Yogyakarta, which according to [2] surveys has the value of the ratio of internet users to the second highest number of citizens (41.5\%) after DKI Jakarta (42, 8\%) by 2013.

Along with its development, fooddelivery service providers began to appear, including in the area of Yogyakarta. There are at least five names of service providers, namely: Go-Food, PesanSaja.com, MakanDiantar.com, Deliv Jogja, and O'Jack. In maintaining its existence, a food-delivery service provider must continuously improve the quality of customer service to keep customers from using the services of competitors.

$\mathrm{XYZ}$ is one of the food-delivery service providers in Yogyakarta that stood since 2014. In its first year, XYZ can serve up to 40 orders per day. However, by the end of the second year of operation since its establishment, the number of orders received by XYZ decreased to 10 to 20 orders per day. This causes XYZ to reduce the number of couriers, from the original five couriers to 3 couriers. This situation is 
caused by the emergence of competitors, especially the national scale company. Therefore, it is important for XYZ to be able to improve the quality of its services in order to increase customer satisfaction and maintain its existence. A national competitor company, in this study called $\mathrm{ABC}$, which entered Yogyakarta since November 2015, is one of the application-based services that has as many as 1,800 couriers, very much in comparison to XYZ. In addition, the other comparison lies in the number of outlets that can be served.

The number of outlets that can be served by XYZ is 39 outlets, while the outlets that can be served by $\mathrm{ABC}$ are more than 500 outlets. The average number of orders served by one competitor's courier in one day is 10 to 15 orders, far more than the order $\mathrm{XYZ}$ receives. Because of some advantages possessed by competitor companies, in this study $\mathrm{ABC}$ is used as a comparison or a competitor. Therefore, this study aimed to identify the attributes of the needs of XYZ's consumers of online food delivery service providers, to find out the level of satisfaction with the quality of their services, and to identify the technical needs of quality improvement of the delivery service.

\section{MATERIAL AND METHOD}

We selected the food-delivery service company based on the self-developed following criteria: (1) not the food delivery service provided by the restaurant/food outlets themselves; (2) provide delivery service from various partner food outlets; (3) use online services; and (4) does not serve other than food. Therefore, from five companies in Yogyakarta, XYZ was selected as the object of the study.

To find out the consumer's needs on XYZ delivery service attributes, four questionnaires with five Likert scales were prepared to determine important level of attribute, consumer's perception on XYZ services, consumer's perception on its competitor services (ABC), and customer expectations of the services. The questionnaires, which were designed from some previous similar study, were distributed to $>700$ respondents who in the last 3 months used the services of the company, out of 2,732 XYZ listed customers in their database. Selection of respondents refers to [3] which states the importance of obtaining consumer ratings shortly after they were receiving such services. The data obtained is then processed using IBM SPSS 20.0 to test whether the statement and question items were valid and reliable through validity test and reliability test.

Servqual approach, developed by [4] was used to identify customer needs attributes through voice of customer based on five dimensions of service quality, namely tangible, reliability, responsiveness, assurance, and empathy. Servqual was also used to find out customer satisfaction, based on gap between perception and expectation. Meanwhile, Quality Function Deployment (QFD) was used to design the technical requirements required by $\mathrm{XYZ}$ in order to meet the attributes of consumer needs. Gap analysis was only done on the gap that occurs between perceived services and expected services. The study was conducted from June 2016 to February 2017.

\section{RESULTS AND DISCUSSION}

\subsection{Attributes of Consumer's Needs}

Based on similar research literature studies, direct observation, and interviews on 30 respondents; we obtained 27 attributes of consumer needs, which are the development of five dimensions of service quality model. After the preliminary questionnaire was distributed and the results of the questionnaire were tested through validity and reliability test, 26 attributes of consumer needs were then used in the main questionnaire (Table 1). Of the 728 questionnaires distributed online, 287 respondents filled in the questionnaire. This means the number of respondents who fill the questionnaire is $39.4 \%$. The filling rate of this online questionnaire is categorized sufficient. According Saldivar [5] the average rate of filling in the questionnaire online by the respondents is $30 \%$. However, of the 287 respondents, only 213 respondents were used in this study. This is because only 213 
respondents are also consumers of $\mathrm{ABC}$ 's competitor companies. Based on the value of consumer interest level (TKK), it can be seen that the attribute of consumer needs with the highest TKK value is "orders received as ordered."

Table1. Attributes of Consumer's Needs

\begin{tabular}{|c|c|}
\hline Dimension & Attribute \\
\hline \multirow{4}{*}{ Tangibles } & Neat and clean courier appearance \\
\hline & Attractive display of website/application \\
\hline & Clean condition of food box used by the courier \\
\hline & User-friendly application to place an order \\
\hline \multirow[t]{5}{*}{ Reliability } & Complete information on websites/application \\
\hline & Good condition (not broken/ messy) of the ordered foods \\
\hline & Affordable delivery cost \\
\hline & Affordable price of the listed outlets partners \\
\hline & Wide coverage area \\
\hline \multirow[t]{4}{*}{ Responsiveness } & Clear explanation from the courier/receptionist \\
\hline & Quick response to customer complaints \\
\hline & Ease tracking of courier position \\
\hline & Reliable information on estimated delivery times \\
\hline \multirow[t]{10}{*}{ Assurance } & Regularly updated information in website/application \\
\hline & Completely listing of outlets partners \\
\hline & Different payment ways \\
\hline & Timely in delivering food \\
\hline & Easy to place order through website / application \\
\hline & Orders received as ordered \\
\hline & Compensation for the wrong order \\
\hline & Accurate price calculation \\
\hline & Availability of change money \\
\hline & Readiness to take and meet all consumer orders \\
\hline \multirow[t]{3}{*}{ Empathy } & Rewards for loyal customers \\
\hline & Friendly and polite courier and receptionist \\
\hline & Consumer-oriented working hours \\
\hline
\end{tabular}

\subsection{Respondents Profile}

The respondents in this study were consumers who during November to December 2016 have used the services of $\mathrm{XYZ}$ and $\mathrm{ABC}$, and were willing to fill out the main questionnaire. Survey on the characteristics of respondents conducted with the aim to determine to which extent the characteristics variation of respondents as consumers XYZ (Table 2).

\subsection{Analysis of QFD}

Once the attribute of consumer needs was known, the assessment of the importance of the attribute for the consumer can be conducted. Analysis of consumer interest level was done with purpose to find out priority of consumer desire. Based on the value of consumer interest level (TKK), it can be seen that the attribute of consumer needs with the highest TKK value is "orders received as ordered."

The XYZ service performance level score was obtained through the main questionnaire, where respondents were asked to assess XYZ's current service performance for each attribute of consumer needs. In addition to the assessment of XYZ service performance level, respondents were also asked to provide an assessment of the service performance of its competitors, namely $\mathrm{ABC}$. This assessment aims to determine $\mathrm{XYZ}$ service performance assessment for consumers and compare it with competitors. From these results, it can be seen that $A B C$ service performance for 
most attributes is better than XYZ. Only on five attributes, $\mathrm{XYZ}$ service performance value greater than $A B C$, that is attribute: clean condition of food box used by the courier; neat and clean courier appearance; compensation for the wrong order; availability of change money; and friendly and polite courier and receptionist. According to Nelson and Bowen uniforms have a positive influence on consumer satisfaction, because the uniforms are encouraging the creation of a positive atmosphere. In addition, also mentioned the appearance of the uniforms are very helpful to create an impression and easily accepted by the social environment and provide motivation to better complete the task well.

Table1. Respondent Profiles

\begin{tabular}{|l|l|r|}
\hline Variable & Definition & $\mathbf{\%}$ \\
\hline \hline \multirow{4}{*}{ Gender } & Male & 11 \\
\cline { 2 - 3 } & Female & 89 \\
\hline \multirow{5}{*}{ Range of age } & $12-16$ & 5 \\
\cline { 2 - 3 } & $17-25$ & 79 \\
\cline { 2 - 3 } service uses & $26-35$ & 14 \\
\cline { 2 - 3 } & $36-45$ & 2 \\
\cline { 2 - 3 } & $46-55$ & 0 \\
\hline \multirow{5}{*}{ Media } & $1-5$ & 62 \\
\cline { 2 - 3 } & $6-10$ & 18 \\
\cline { 2 - 3 } & $11-15$ & 8 \\
\cline { 2 - 3 } & $16-20$ & 2 \\
\cline { 2 - 3 } & $21-25$ & 2 \\
\cline { 2 - 3 } & $>25$ & 2 \\
\hline & Line & 2 \\
\cline { 2 - 3 } & Whatsapp & 2 \\
\cline { 2 - 3 } & Telephone & \\
\cline { 2 - 3 } & SMS & \\
\hline
\end{tabular}

In addition to $\mathrm{XYZ}$ service performance level and its competitor's ABC, respondents were also asked to provide an assessment of the expected value of consumers on XYZ service performance. The service performance values were expected to be obtained through the main questionnaire, where respondents were asked to provide the value of the expected XYZ performance for each attribute of the consumer needs. After the expectation value was known gap analysis to find out customer satisfaction on $\mathrm{XYZ}$ service performance, which has been accepted, then can be performed. Gap analysis was done by subtracting the current $\mathrm{XYZ}$ service level performance level (perception) with the expected XYZ service performance value (expectation). From these results, it can be seen that all attributes have a negative gap value, which means that consumers have not been satisfied with XYZ service performance that has been accepted because the value of consumer perception is lower than the expectation value. Assessment of consumer expectations on service performance $\mathrm{XYZ}$ then used as a consideration in determining the value of future goals. To fulfill the customer's satisfaction, it is necessary to determine the future goal, that is the determination of service performance target XYZ for the future or show the improvement value to be achieved. The value of future goals is obtained through interviews with XYZ management. In addition to considering the value of consumer expectations for $\mathrm{XYZ}$ service performance, other things considered in determining the value of future objectives are the current conditions, capabilities of the company, resources owned, and constraints to be faced. Satisfied customers tend to reuse the services in the future. This means satisfaction is a key factor for consumers in repurchasing which is the largest portion of the company's sales volume [6].

The improvement ratio is the result of comparison between XYZ service performance goal values in the future (goal) with XYZ service performance value at present. Determination of the ratio of improvement is required to provide information for the management of how much effort to be done in meeting the attributes of consumer needs. The greater the value of the improvement ratio indicates the lower the current service performance and the greater the necessary corrective action. The ratio has a different meaning, ranging from 'no change' if less than 1, moderate improvement' if the value falls within the range of 1 to 1.5 , and means 'total improvement' if the value is greater than 1.5 [7].

The sales point is information about the effect of changes in an attribute on the level of sales that occurred. The value at the point of sale means that an attribute of the customer's needs if the change takes place will have a positive impact on sales increase 
and have more priority for improvement. The selling point was obtained through interviews with the management of XYZ by considering the value of consumer importance. Criteria, developed by [8], described the meaning of sales point, ranging from 'no influence'; 'moderate influence'; and significant influence for these values respectively $1 ; 1.2$; and 1.5 .

The scale of consumer interest (SKK) is information about the order of improvement of attributes of consumer needs that can be done by the management. SKK is determined based on three variables: customer satisfaction level, improvement ratio, and point of sale. Normalization of Consumer Interest Scale (NSKK) shows complete information on the priority of customer needs. NSKK is a percentage of the value of SKK. The higher the value of SKK then the NSKK value will also be higher. If the value of SKK and NSKK is higher than the priority for improvement will be greater. From these results, it is known that the attribute that has the highest NSKK value is "list of outlets (restaurant / restaurant) complete" with a value of $4.79 \%$ NSKK. Because it has the highest NSKK value then this attribute becomes a priority to be improved because these attributes are very influential on customer satisfaction.

\subsection{Determining Technical Requirements}

Technical requirements were determined by translating voice of customer of the XYZ. The design of these requirements was communicated with the management of the company. The management then studied the possibility of applying the technical requirement design.

Relationship between each consumer's need and designed technical requirement was analyzed and mapped into a matrix to find out how strong its relations. The matrix can help the management in determining the priority of improvement (Fig.1). The relationship between the technical needs explains how the relationship of one technical need with other technical needs, whether technical requirements can be mutually supportive (positive relationship) or interdependent (negative relationship). The relationship between technical requirements is determined by the influence of other technical needs. There are 52 relationships between technical needs at House of Quality (Fig.1). The relationship consists of 27 strong positive relationships, 22 positive relationships, 1 strong negative relationship, and 1 negative relationship. A strong positive and positive relationship means that the fulfillment of each technical need is mutually supportive, but in a strong negative and negative relationship it means that fulfilling a technical requirement will decrease the fulfillment of other technical needs.

The negative relation existed between "courier is capable to handle several orders in the adjacent areas" and "adding more couriers". The reason given negative relationship is because by increasing the number of couriers then the service capacity will increase so that the number of orders must be divided equally to each courier so that each messenger gets the quota to send orders evenly because the number of orders handled by courier in a day will determine the incentives given.

Strong negative correlation was existed between "twice confirmation on consumer's order" and "providing new orders". The reason was because the purpose of making two confirmations is to make sure the order that gets to the consumer is correct, while the goal of delivering a new order is to replace the wrong order. So when the technical requirement to do two confirmations is done then the possibility of wrong order will be small so that the technical requirement of giving new order do not need to be done.

Determining the difficulty level of the realization of technical needs is needed to determine the difficulty level of the application of technical requirements tailored to the capabilities and conditions of the company. Determining the difficulty level helps management in selecting service attributes that are easy to fix immediately, and these attributes have a high priority for immediate correction. The difficulty level of the technical requirement is obtained through interview with XYZ management (Fig.1). 


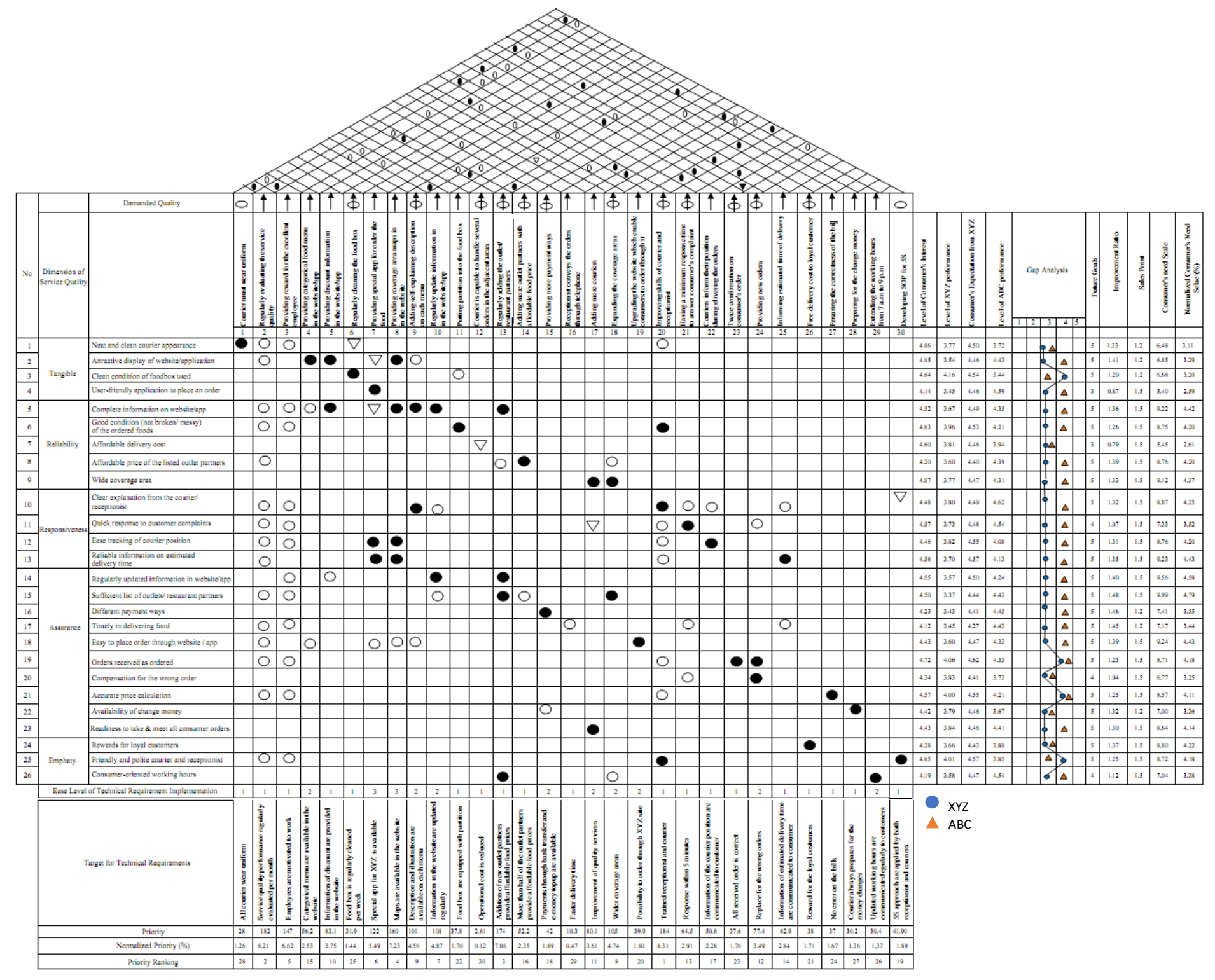

Figure 1. House of Quality 
Determination of priorities and normalization was done with the aim to know the priority ranking for each technical requirement. It is impossible to carry out all the technical requirements at the same time, therefore, it is important to determine what technical needs are priority to be realized first. After knowing the rankings then the management can follow the order of priority in an effort to improve service performance (Fig.1).

House of Quality (HoQ) is a summary of the overall results of all the calculations that have been done. The usefulness of the HoQ is to simplify the interpretation of the QFD method, which is then used as a reference for service system improvement in XYZ (Fig.1).

\section{CONCLUSIONS}

The five attributes of consumer needs with the top rank of interest were "orders received as ordered", "friendly and polite courier and receptionist", "adding partition into the food box", "orders received in good condition", and "affordable delivery cost". The XYZ consumers were not satisfied with XYZ's current performance, judging from the negative gap.

The top five priority technical needs are "improving skills of courier and receptionist", "service quality performance regularly evaluated", "addition of new outlet partners regularly", "to load maps on the website", and "to provide rewards for outstanding employees".

\section{REFERENCES}

[1] Asosiasi Penyelenggara Jasa Internet Indonesia - APJII, Profil Pengguna Internet Indonesia 2014. Jakarta: Asosiasi Penyelenggara Jasa Internet Indonesia, 2015.

[2] Badan Pusat Statistik dan Asosiasi Penyelenggara Jasa Internet Indonesia, "Indonesia Internet Usage for Business Sector 2013," Jakarta, 2016.

[3] K. LaTour and L. Carbone, "Sticktion: Assessing Memory for the Customer
Experience.," Focus Cust. Relatsh. Manag., vol. 55, no. 4, pp. 342-353, 2014.

[4] A. Parasuraman, V. A. Zeithaml, and L. L. Berry, "SERQUAL: A Multiple-Item scale for Measuring Consumer Perceptions of Service Quality," J. Retail., vol. 64, p. 28, 1988.

[5] M. Saldivar, A Primer on Survey Response Rate. Florida: Florida State University, 2012.

[6] F. Tjiptono and G. Chandra, Service Quality and Satisfaction. Yogyakarta: Penerbit ANDI, 2005.

[7] S. T. Foster, Managing Quality: An Integrative Approach. Pearson Prentice Hall, 2004.

[8] L. Cohen, Quality Function Deployment: How to Make QFD Work for You. Addison-Wesley, 1995. 